\title{
Respon Polikultur Cabai Rawit Dan Sawi Terhadap Waktu Pengomposan Dan Dosis Kompos Kulit Bawang Merah
}

\author{
Peileku Yikwa dan Luluk Syahr Banu \\ Program Studi Agroteknologi Fakultas Pertanian Universitas Respati Indonesia Jakarta \\ Email: luluksyahrbanu@gmail.com
}

\begin{abstract}
ABSTRAK
Polikultur tanaman di polibag merupakan salah satu teknologi pertanian perkotaan yang murah dan sederhana. Media tanam yang dapat digunakan adalah limbah rumah tangga seperti kompos kulit bawang merah. Metode ini memiliki manfaat yang besar bagi kesehatan lingkungan dan ketahanan pangan masyarakat perkotaan. Tujuan penelitian adalah mengetahui respon polikultur tanaman bawang merah dan sawi terhadap waktu pengomposan dan dosis kompos kulit bawang merah. Penelitian dilaksanakan di Rumah Kaca Fakultas Pertanian Universitas Respati Indonesia pada bulan Februari sampai Agustus 2019. Penelitian dilakukan dengan metode eksperimental menggunakan Rangcangan Acak Lengkap (RAK) Faktorial, yang terdiri atas faktor pertama yaitu dosis kompos limbah kulit bawang merah ( $\mathrm{PO}=$ tanpa pemberian kompos limbah kulit bawang merah (kontrol), $\mathrm{P} 2=$ dosis limbah kulit bawang merah $100 \mathrm{gr} /$ polybag, P3= dosis limbah kulit bawang merah $150 \mathrm{gr} / \mathrm{polibag}$, dan P4= dosis limbah kulit bawang merah 200 gr/polibag) dan faktor kedua yaitu waktu pengomposan (W1 = 24 jam dan W2 = 36 jam). Semua perlakukan diulang sebanyak 4 ulangan sehingga diperoleh 32 satuan percobaan. Paramater yang diamati meliputi tanaman cabai rawit (tinggi tanaman, bobot basah, dan bobot buah) serta tanaman sawi (tinggi tanaman, jumlah daun, dan bobot basah). Hasil penelitian menunjukkan pemberian kompos umur 36 jam sebanyak 100 gram/polibag pada tanaman cabai rawit dan sawi yang ditanam secara polikultur menggunakan polibag menghasilkan bobot tanaman dan bobot buah cabai rawit yang paling tinggi yaitu masing-masing 211,25 gram dan 73,25 gram.
\end{abstract}

Kata Kunci : Pertanian perkotaan, polikultur, kompos kulit bawang merah, cabai rawit, sawi

\begin{abstract}
Plant polyculture in polybags is one of the inexpensive and simple urban agricultural technologies. Growing media that can be used are household waste such as compost onion skin. This method has great benefits for environmental health and food security of urban communities. The purpose of this study was to determine the polyculture response of shallot and mustard plants to the composting time and compost dose of shallot skin. The study was conducted at the Greenhouse of the Faculty of Agriculture, University of Respati Indonesia in February to August 2019. The research was conducted using an experimental method using a Completely Randomized Design (RAK) Factorial, which consisted of the first factor, namely the compost dose of onion skin waste $(\mathrm{PO}=$ without the provision of compost waste shallot peel (control), P2 = onion peel waste dose $100 \mathrm{gr} /$ polybag, P3 = onion peel waste dose $150 \mathrm{gr} /$ polybag, and $\mathrm{P} 4$ = onion peel waste dose $200 \mathrm{gr} /$ polybag) and the second factor is composting time (W1 $=24$ hours and $W 2=36$ hours). All treatments were repeated 4 replications to obtain 32 experimental units. Parameters observed included cayenne pepper (plant height, wet weight and fruit weight) and mustard plants (plant height, number of leaves, and wet weight). The results showed that giving 36 hours of compost aged as much as 100 grams / polybag in
\end{abstract}

http://ejournal.urindo.ac.id/index.php/pertanian

Article History :

Sumbitted 11 Juni 2020, Accepted 29 Juni 2020, Published 30 Juni 2020 


\section{Jurnal IImiah Respati}

cayenne pepper plants and mustard plants grown in poly-culture using polybag produced the highest plant weight and weight of cayenne pepper, which were 211.25 grams and 73.25 grams, respectively.

Keywords: Urban agriculture, polyculture, shallot skin compost, cayenne pepper, mustard greens

\section{PENDAHULUAN}

Seiring dengan meningkatnya jumlah penduduk, maka kebutuhan pangan semakin meningkat, hal ini berakibat pada meningkatnya sisa buangan berupa sampah atau limbah baik rumah tangga, pabrik, maupun industri. Limbah yang didapatkan sebagai agen pencemar dapat diberdayakan menjadi bahan yang lebih bermanfaat, salah satunya adalah limbah kulit bawang merah. Limbah tersebut dapat diolah menjadi pupuk organik yang berbahan limbah kulit bawang merah [1]. Dosis kompos pupuk organik adalah semua sisa bahan tanaman dan kotoran hewan yang mempunyai kandungan unsur hara yang rendah. Macam pupuk organik adalah kompos, pupuk hijau dan pupuk kandang. Peranan pupuk organik cukup besar dalam memperbaiki sifat fisik, kimia dan biologis tanah serta lingkungan. Pupuk organik didalam tanah akan dirombak oleh organisme tanah menjadi humus atau bahan organik tanah [2].

Cabai rawit dan sawi merupakan tanaman musiman yang tumbuh di daerah dengan iklim tropis. Tanaman ini dapat tumbuh dan berkembang biak didataran tinggi maupun dataran rendah. Hampir semua jenis tanah yang cocok untuk budidaya tanaman pertanian, cocok pula bagi tanaman cabai rawit dan sawi. Untuk mendapatkan kuantitas dan kualitas hasil yang tinggi, cabai rawit dan sawi cocok dengan tanah yang subur, gembur,dan tambahan pupuk organik dengan dosis kompos organik yang tepat. Kompos yang dihasilkan dari limbah pertanian sesuai untuk tambahan nutrisi tanaman cabai dan sawi, contohnya adalah kompos kulit bawang merah. Hal ini disebabkan karena ekstrak kulit bawang merah mengandung calsium (Ca) yang merupakan unsur hara yang dibutuhkan tanaman selain nitrogen, posfor, kalium, magnesium dan belerang. Pertumbuhan dan produksi tanaman cabai rawit dan sawi berkaitan erat dengan fisiologi tumbuhan cabai rawit dan sawi, karena ekstrak kulit bawang merah mampu menjadi perangsang tumbuh bagi tanaman yang menggunakan sistem polikultur [3]. Mengingat kandungan yang dimiliki oleh kulit bawang merah sangat banyak dan terdapat zat-zat yang dibutuhkan oleh suatu tumbuhan guna menunjang pertumbuhannya, maka perlu dilakukan suatu pengujian terhadap kulit bawang merah tersebut untuk mendapatkan hasil 


\section{Jurnal IImiah Respati}

yang empiris. Kedua tanaman sayuran ini dapat dilakukan dengan cara tumpang sari dan polikultur. Penanaman Polikultur juga dapat menjadi alternatif untuk solusi lahan sempit dengan tetap menjaga pertumbuhan tetap maksimal. Berdasarkan uraian di atas peneliti merencanakan penelitian dengan judul respon polikultur cabai rawit dan sawi terhadap waktu pengomposan dosis kompos kulit bawang merah. Tujuan penelitian ini adalah mengetahui respon polikultur tanaman bawang merah dan sawi terhadap waktu pengomposan dan dosis kompos kulit bawang merah.

\section{METODE}

\section{Bahan dan Alat}

Bahan yang di gunakan dalam penelitian ini meliputi tanah, pupuk kompos kulit bawang merah, benih cabai rawit varietas cabai hijau keriting, dan sawi hijau varietas caisim sedangkan alat yang digunakan adalah polibag ukuran $40 \mathrm{~cm}$, timbangan digital, cangkul, dan gembor.

\section{Rancangan Penelitian}

Penelitian ini merupakan penelitian eksperimen, rancangan yang di gunakan dalam penelitian ini adalah Rangcangan Acak Lengkap (RAK) Faktorial. Kombinasi yang terdiri atas 2 faktor yaitu dosis kompos kulit bawang merah dan waktu pengomposan yang diulang sebanyak 4 ulangan, sehingga total unit percobaan adalah 32 satuan percobaan. Dosis kompos limbah kulit bawang merah dan waktu pengomposan yang digunakan sebagai berikut:

Dosis kompos $(\mathrm{P})$ :

$\mathrm{PO}=$ tanpa pemberian kompos limbah kulit bawang merah (kontrol)

P1= dosis limbah kulit bawang merah 50 (gr)/polibag

P2= dosis limbah kulit bawang merah 100 (gr) /polibag

P3= dosis limbah kulit bawang merah 150 (gr) /polibag

Waktu pengomposan (W) :

$\mathrm{W} 1=24$ jam

$\mathrm{W} 2=36$ jam

\section{Cara Kerja}

1. Persiapan limbah kulit bawang merah

Media tanam yang digunakan adalah tanah dan pupuk dosis, limbah kulit bawang merah dengan perbadingan sesuai perlakuan dan pupuk organik sesuai dosis yang telah di buat.

2. Penyemaian

Penyemaian dilakukan dengan cara menyemai cabai rawit dan sawi di polibag dengan ukuran $10 \times 10 \mathrm{~cm}, 1$ polibag 3 benih, untuk pindah tanam berdaun 3-4 helai, tinggi tanaman sekitar 2-4 cm, sekitar 1 minggu.

3. Penanaman

Penanaman sebaiknya dilakukan pada pagi hari atau sore hari agar tanaman tidak mengalami stres, bibit cabai rawit dan sawi 
sebelum di pindahkan ke polibag sebaiknya polibag di buka terlebih dahulu,setelah itu baru di pindakan ke polibag yang lebih besar dengan ukuran $40 \times 40 \mathrm{~cm}$.

4. Pemeliharaan Tanaman

a. Penyiraman

Tanaman cabai rawit dan sawi membutuhkan pengairan terutama pada saat fase vegetatif oleh sebab itu penyiraman sebaiknya di lakukan secara rutin pagi dan sore hari agar tanaman cabai rawit dan sawi dapat tumbuh dengan baik.

b. Penyiangan

Dalam melakukan penyiaman disesuaikan dengan kondisi pertumbuhan gulma yang tumbuh di sekitar tanaman, penyiangan di lakukan dengan cara manual dengan cara mencabut gulma yang tumbuh disekitar tanaman cabai rawit dan sawi penyiangan dilakukan dengan hati-hati agar perakaran tanaman tidak tergangu.

c. Pemupukan

Pemupukan tanaman cabai rawit dan sawi sesuai dengan perlakuan.

\section{d. Pemanenan}

Waktu panen sawi dilakukan mulai umur 30-60 hari setelah tanam dari bibit segera dipanen.

\section{Variabel Penelitian}

\section{Cabai Rawit}

a. Tinggi Tanaman $(\mathrm{cm})$

Pengamatan pada tinggi tanaman dimulai pada 7 HST,sampai panen dengan interval 7 hari sekali. Tinggi tanaman di ukur dari pangkal batang sampai titik tumbuh.

b. Bobot buah (gr)

Ditimbang hasil panen buah yang diperoleh dengan cara menimbang hanya buah yang sudah dipanen penimbangan di gunakan dengan timbangan digital.

c. Bobot basah tanaman (gr) Bobot basah tanaman diperoleh dengan cara menimbang keseluruhan batang dan daun, menimbang digunakan dengan timbangan digital.

Sawi

a. Tinggi Tanaman $(\mathrm{cm})$

Pengamatan pada tinggi tanaman di mulai pada 7 HST,sampai panen dengan interval 7 hari sekali.Tinggi tanaman di ukur dari pangkal batang sampai titik tumbuh.

b. Jumlah Daun (helai) Pengamatan jumlah daun dimulai 7 HST dengan cara menghitung jumlah daun yang sudah mekar secara lengkap dan waktu pengamatan di lakukan setiap 7 hari sekali sampai panen.

c. Bobot basah tanaman (gr)

Bobot basah tanaman di peroleh dengan cara menimbang keseluruhan batang dan daun menggunakan timbangan digital.

\section{Analisis Data}

http://ejournal.urindo.ac.id/index.php/pertanian 
Analisis statistik dilakukan dengan menggunakan uji $\mathrm{F}$ ANOVA, apabila hasil menunjukkan perlakuan berbeda nyata maka dilakukan uji Beda Nyata Terkecil (BNT). Analisis dilakukan pada selang kepercayaan $95 \%(\alpha=0,05)$ menggunakan program SPSS.

\section{HASIL DAN PEMBAHASAN}

\subsection{Pengaruh Kompos Kulit Bawang \\ Merah Terhadap Tinggi Tanaman \\ Cabai Rawit $(\mathrm{cm})$}

\begin{abstract}
Pengamatan tinggi tanaman dilakukan 4 kali yaitu pada 7 HST, sampai dengan 84 HST. Data hasil pengamatan kemudian dianalisis menggunakan uji $\mathrm{F}$ dan untuk mengetahui perbedaan antar perlakuan dilakukan uji BNT (Beda Nyata Terkecil) yang hasilnya sebagaimana tertera pada Tabel 1 dan Tabel 2.
\end{abstract}

Tabel 1. Rekapitulasi hasil uji bnt pengaruh perlakuan terhadap tinggi tanaman cabai 7 HST -42 HST

\begin{tabular}{lllllll}
\hline \multirow{2}{*}{ Perlakuan } & \multicolumn{5}{c}{ Rata-rata Tinggi Tanaman cabai rawit (gr) } \\
\cline { 2 - 6 } & 7 HST & 14 HST & 21 HST & 28 HST & 35 HST & 42 HST \\
\hline P0W0 & $4,62 \mathrm{a}$ & 5,52 & 7,85 & 19,55 & 27,32 & 35,37 \\
P1W1 & $4,82 \mathrm{ab}$ & 6,35 & 8,75 & 23,05 & 31,87 & 38,50 \\
P1W2 & $5,55 \mathrm{ab}$ & 6,45 & 10,92 & 19,87 & 28,20 & 36,80 \\
P2W1 & $6,32 \mathrm{~b}$ & 6,82 & 11,47 & 25,35 & 33,65 & 44,42 \\
P2W2 & $7,27 \mathrm{~b}$ & 8,05 & 12,75 & 27,42 & 34,50 & 53,80 \\
P3W1 & $6,30 \mathrm{~b}$ & 7,42 & 10,42 & 23,02 & 30,70 & 40,92 \\
P3W2 & $4,57 \mathrm{a}$ & 5,55 & 9,00 & 21,12 & 30,02 & 45,22 \\
\hline
\end{tabular}

Keterangan : angka-angka yang diikuti huruf yang sama pada kolom yang sama berarti tidak berbeda nyata menurut uji BNT 5\%. (P0 = tanpa kompos kulit bawang merah, P1 = $50 \mathrm{gr}$ kompos/polibag, P2 = $100 \mathrm{gr} /$ polibag, $\mathrm{P} 3=150 \mathrm{gr} / \mathrm{polibag}, \mathrm{W} 1$ = umur kompos 24 jam, W2 = umur kompos 36 jam)

Hasil analisis sidik ragam menunjukkan perbedaan yang nyata pada umur 7 HST, 14 HST, 21 HST, 42 HST, dan 63 HST. Artinya pemberian perlakuan memberikan adanya pengaruh terhadap tinggi tanaman. Sedangkan pada umur 28 HST, 35 HST, 49 HST, 56 HST, 70 HST, 77 HST dan 84 HST, tidak menunjukkan pengaruh yang signifikan artinya pemberian perlakuan memberikan pengaruh yang sama dengan kontrol. Berdasarkan penelitian, peningkatan tinggi tanaman cabai rawit selama penanaman yang menunjukkan bahwa tanaman cabai mengalami

http://ejournal.urindo.ac.id/index.php/pertanian 


\section{Jurnal IImiah Respati}

pertumbuhan sesuai dengan pertambahan umurnya. Selain itu, dapat pula dilihat bahwa tanaman cabai rawit yang diberi perlakuan kompos kulit bawang merah memiliki tinggi tanaman yang lebih besar dibandingkan kontrol. Hal ini karena kandungan unsur hara yang terkandung dalam pupuk kompos kulit bawang merah terserap, dan tinggi tanaman merupakan salah satu tolak ukur dalam pengamatan tanaman, baik sebagai parameter maupun indikator yang dipergunakan untuk mengukur pengaruh lingkungan dan perlakuan pengamatan yang diterapkan [4].

Tabel 2. Rekapitulasi hasil uji bnt pengaruh perlakuan terhadap tinggi tanaman 49 HST - 84 HST

\begin{tabular}{lllllll}
\hline \multirow{2}{*}{ Perlakuan } & \multicolumn{5}{c}{ Rata-rata Tinggi Tanaman cabai rawit (cm) } \\
\cline { 2 - 7 } & 49 HST & 56 HST & 63 HST & 70 HST & 77 HST & 84 HST \\
\hline P0W0 & 48,62 & 37,50 & 40,05 & 64,82 & 83,85 & 88,12 \\
P1W1 & 42,07 & 59,62 & 57,27 & 70,40 & 82,55 & 87,82 \\
P1W2 & 41,80 & 56,30 & 42,97 & 70,15 & 69,67 & 83,00 \\
P2W1 & 48,55 & 63,67 & 52,82 & 73,12 & 76,80 & 83,05 \\
P2W2 & 53,12 & 69,10 & 57,70 & 74,75 & 77,30 & 90,50 \\
P3W1 & 52,30 & 60,05 & 46,15 & 72,90 & 71,40 & 82,00 \\
P3W2 & 42,25 & 61,10 & 46,05 & 74,72 & 79,20 & 87,92 \\
\hline
\end{tabular}

Keterangan : angka-angka yang diikuti huruf yang sama pada kolom yang sama berarti tidak berbeda nyata menurut uji BNT 5\%. (P0 = tanpa kompos kulit bawang merah, P1 = $50 \mathrm{gr}$ kompos/polibag, $\mathrm{P} 2=100 \mathrm{gr} /$ polibag, $\mathrm{P} 3=150 \mathrm{gr} /$ polibag, $\mathrm{W} 1=$ umur kompos 24 jam, W2 = umur kompos 36 jam)

Kandungan unsur hara pupuk kompos kulit bawang merah mengandung belerang yang memberikan kesuburan bagi tanaman sehingga dapat mempercepat tumbuhnya buah dan bunga pada tumbuhan, yang cukup tinggi. Campuran pupuk kompos kulit bawang merah memberikan pengaruh yang berbeda nyata terhadap tinggi tanaman, jumlah daun, dan biomassa tanaman. Pada umur 84 HST memperlihatkan bahwa tinggi tanaman tertinggi yaitu perlakuan P2W2 dan tinggi tanaman terendah yaitu P3W1. Hal ini disebabkan setiap tanaman memiliki batas konsentrasi jumlah kebutuhan unsur hara yang berbeda-beda. Hasil tanaman tidak ditentukan oleh unsur hara $\mathrm{N}, \mathrm{P}$ dan $\mathrm{K}$ yang diperlukan dalam jumlah banyak 
tetapi oleh mineral seperti magnesium dan materi kimia lainnya seperti oksigen, posfor yang diperlukan dalam jumlah sedikit untuk pertumbuhan jadi hal ini berkaitan dengan hasil penelitian yang di lakukan dimana tinggi tanaman cabai rawit bertambah dengan penambahan kompos kulit bawang merah.

Pada umur 70, 77 dan 84 HST tidak berpengaruh signifikan. Hal ini dikarenakan cabai pada saat umur demikian, hanya membutuhkan kompos kulit bawang merah yang sedikit atau sebagai faktor pembatas. Faktor pembatas juga bisa dilihat dari konsentrasi yang terlalu tinggi atau terlalu rendah, hal ini sesuai dengan perlakuan (P3W1), karena asupan kompos berlebihan justru membuat tanaman tidak dapat tumbuh dengan baik. Selain itu, pertambahan tinggi tanaman dipengaruhi oleh unsur fosfor. Fosfor mempercepat pertumbuhan dan perkembangan ujung akar dan titik tumbuh tanaman. Peran Fosfor bagi tumbuhan antara lain memacu pertumbuhan akar dan pembelahan sistem perakaran yang baik dari benih dan tanaman muda, mempercepat pemasakan buah dan biji, dan mempercepat presentase pembentukan bunga menjadi buah [5].

\subsection{Pengaruh Kompos Kulit Bawang \\ Merah Terhadap Bobot Basah Tanaman Cabai Rawit}

Pengamatan bobot basah tanaman dilakukan 12 kali yaitu pada 7 HST, 14 HST, 21 HST, 28 HST, 35 HST, 42 HST, 49 HST, 56 HST, 63 HST, 70 HST, 77 HST, dan 84 HST . Data hasil pengamatan kemudian dianalisis menggunakan uji $\mathrm{F}$ dan untuk mengetahui perbedaan antar perlakuan dilakukan Uji Nyata Terkecil (BNT). Berdasarkan hasil penelitian, pengaruh pemberian pupuk kompos kulit bawang merah terhadap tinggi tanaman dapat dilihat pada Tabel 3.

Berdasarkan Tabel 3. nilai rataan bobot basah tanaman cabai secara berurutan (P2W2) 211,25 gram, (P3W2) 189,25 gram, (P3W1) 174,75 gram, (P1W1) 164,75 gram, (P1W2) 148,75 gram, (P2W1) 116,75 gram dan (POWO) 105,00 gram. Guna mengetahui pengaruh perlakuan terhadap berat basah maka dilakukan analisis sidik ragam. Hasil analisis sidik ragam dapat dilihat bahwa adanya pengaruh yang signifikan $(p<0,05)$ pada berat basah tanaman cabai. Perlakuan POWO menghasilkan bobot basah tanaman cabai terendah $(105,00)$ gram dan perlakuan (P2W2) terbesar (211,25 gram).

Pada perlakuan PoWo menunjukkan bobot basah terendah, hal ini disebabkan karena berat suatu tanaman pada dasarnya dipengaruhi oleh tinggi tanaman dan jumlah daun yang mengalami fotosintesis. Semakin banyak jumlah daun maka proses fotosintesis akan berjalan dengan baik. Tingginya proses fotosintesis 


\section{Jurnal IImiah Respati}

akan menghasilkan energi yang lebih besar

untuk pertumbuhan dan perkembangan tanaman.

Semakin banyak jumlah daun akan berpengaruh positif pada berat kering tanaman, hal ini terbukti bahwa semakin tinggi rataan tinggi tanaman cabai akan meningkatkan berat basah tanaman cabai yaitu pada perlakuan (P2W2) dengan penambahan pupuk dosis kulit bawang merah 100 (gram) /polibag dihasilkan rerata berat basah tertinggi dibandingkan perlakuan lainnya. Disisi lain kadar air pada suatu tanaman juga berpengaruh pada berat basah tanaman, semakin sedikit kadar air maka berat basah tanaman semakin sedikit dan semakin banyak kadar air maka berat basah relatif besar [6].

Tabel 3. Rataan Hasil Uji BNT Pengaruh Perlakuan Terhadap Bobot Basah Cabai

\begin{tabular}{cc}
\hline Perlakuan & Rata-rata Bobot Basah (gram) \\
\hline P0W0 & $105,00 \mathrm{a}$ \\
P1W1 & $164,75 \mathrm{a}$ \\
P1W2 & $148,75 \mathrm{a}$ \\
P2W1 & $116,75 \mathrm{a}$ \\
P2W2 & $211,25 \mathrm{~d}$ \\
P3W1 & $174,75 \mathrm{~b}$ \\
P3W2 & $189,25 \mathrm{c}$
\end{tabular}

Keterangan: angka dalam satu kolom yang diikuti huruf yang sama menunjukkan tidak berbeda nyata pada Uji BNT 5\% (P0=tanpa kompos kulit bawang merah, $\mathrm{P} 1=50 \mathrm{gr}$ kompos/polibag, P2=100 gr/Polibag, P3 =150 gr/polibag, W1 umur kompos 24 jam, W2= umur kompos 36 jam)

\subsection{Pengaruh Kompos Kulit Bawang Data hasil pengamatan kemudian dianalisis Merah Terhadap Bobot Buah menggunakan uji $\mathrm{F}$ dan untuk mengetahui \\ Tanaman Cabai Rawit \\ Pengamatan bobot buah tanaman dilakukan 12 kali yaitu pada 7 HST, 14 HST, 21 HST, 28 HST, 35 HST, 42 HST, 49 HST, 56 HST, 63 HST, 70 HST, 77 HST, dan 84 HST . perbedaan antar perlakuan dilakukan Uji Nyata Terkecil (BNT). Berdasarkan hasil penelitian, pengaruh pemberian pupuk padat terhadap tinggi tanaman dapat dilihat pada Tabel 4.}


Tabel 4. Rataan Hasil Uji BNT Pengaruh Perlakuan Terhadap Bobot Buah Cabai

\begin{tabular}{cc}
\hline Perlakuan & Rata-rata Bobot Buah Cabai (gram) \\
\hline P0W0 & $28,50 \mathrm{~b}$ \\
P1W1 & $66,25 \mathrm{a}$ \\
P1W2 & $58,25 \mathrm{ab}$ \\
P2W1 & $45,00 \mathrm{ab}$ \\
P2W2 & $73,25 \mathrm{a}$ \\
P3W1 & $72,50 \mathrm{a}$ \\
P3W2 & $67,25 \mathrm{a}$ \\
\hline
\end{tabular}

Keterangan: angka dalam satu kolom yang diikuti huruf yang sama menunjukkan tidak berbeda nyata pada Uji BNT 5\%. (P0=tanpa kompos kulit bawang merah, P1=50 gr kompos/polibag, P2=100 gr/Polibag, P3 =150 gr/polibag, W1 umur kompos 24 jam, W2= umur kompos 36 jam)

Berdasarkan Tabel 4, nilai rataan
bobot basah tanaman cabai secara
berurutan (P2W2) 73,22 gram, (P3W1)
72,50 gram, (P3W2) 67,25 gram, (P1W1)
66,25 gram, (P1W2) 58,25 gram, (P2W1)
45,00 gram dan (POW0) 28,50 gram. Guna
mengetahui pengaruh perlakuan terhadap
berat basah maka dilakukan analisis sidik

ragam. Hasil analisis sidik ragam menunjukkan adanya pengaruh yang signifikan $(p<0,05)$ pada berat buah cabai. Perlakuan POWO menghasilkan bobot basah tanaman cabai terendah $(105,00$ gram) dan perlakuan (P2W2) terbesar (211,25 gram). Pada semua perlakuan menunjukkan perbedaan yang signifikan dengan kontrol. Hal ini dapat dikatakan bahwa pemberian perlakuan memberikan pengaruh yang nyata terhadap bobot buah cabai rawit. Pemberian kompos kulit bawang merah lebih mudah terurai dan mengandung banyak unsur hara sehingga dapat memperbaiki struktur tanah. kompos kulit bawang merah berkaitan erat dengan fisiologi pertumbuhan cabai yang mampu menjadi perangsang tumbuh bagi cabai rawit sehingga pertumbuhan dan produksi tanaman cabai rawit sangat baik.

\subsection{Pengaruh Kompos Kulit Bawang Merah Terhadap Tingi Tanaman Sawi \\ Pengamatan tinggi tanaman sawi} dilakukan 4 kali yaitu pada 7 HST, 14 HST, 21 HST, dan 28 HST. Data hasil pengamatan kemudian dianalisis menggunakan uji $\mathrm{F}$ dan untuk mengetahui perbedaan antar perlakuan dilakukan Uji Beda Nyata Terkecil (BNT). Berdasarkan hasil penelitian, respon polikultur cabai rawit terhadap waktu pengomposan dan dosis kompos kulit bawang merah dapat dilihat pada Tabel 5. 
Tabel 5. Rataan Hasil Uji BNT Pengaruh Perlakuan Terhadap Tinggi Tanaman Sawi

\begin{tabular}{lllll}
\hline \multirow{2}{*}{ Perlakuan } & \multicolumn{4}{c}{ Rata-rata Tinggi tanaman Sawi $(\mathbf{c m})$} \\
\cline { 2 - 5 } & 7 HST & 14 HST & 21 HST & 28 HST \\
\hline P0W0 & 3,95 & 4,2 & 6,80 & 9,13 \\
P1W1 & 4,08 & 4,23 & 7,25 & 9,78 \\
P1W2 & 4,15 & 4,87 & 5,10 & 8,93 \\
P2W1 & 3,20 & 4,00 & 5,65 & 8,23 \\
P2W2 & 3,07 & 3,75 & 6,27 & 10,12 \\
P3W1 & 4,27 & 4,77 & 6,90 & 9,95 \\
P3W2 & 2,97 & 3,63 & 7,70 & 9,45 \\
\hline
\end{tabular}

Keterangan: angka dalam satu kolom yang diikuti huruf yang sama menunjukkan tidak berbeda nyata pada Uji BNT 5\%. (P0=tanpa kompos kulit bawang merah, P1=50 gr kompos/polibag, P2=100 gr/Polibag, P3 =150 gr/polibag, W1 umur kompos 24 jam, W2= umur kompos 36 jam).

Data pengamatan tinggi dan daftar sidik ragamnya tanaman sawi pada umur 7 HST, 14 HST, 21 HST dan 28 HST disajikan pada lampiran. Dari daftar sidik ragam menunjukkan bahwa perlakuan dengan dosis kompos kulit bawang merah dan waktu pengomposan berpengaruh tidak nyata terhadap tinggi tanaman pada semua umur pengamatan. Interaksi antara dosis kompos kulit bawang merah dengan waktu pengomposan pun berpengaruh tidak nyata terhadap tinggi tanaman pada semua umur pengamatan. Rataan tinggi tanaman sawi pada umur 7 HST, 14 HST, 21 HST dan 28 HST dapat dilihat pada Tabel 5. Pola budidaya pada perlakuan P2W2 dan P2W1 memperlihatkan perbedaan yang sangat nyata pada umur 35 HST. Dimana perlakuan P2W2 memperlihatkan tinggi tanaman tertinggi $(10,12 \quad \mathrm{~cm}) \quad$ sedangkan P2W1 memperlihatkan tinggi tanaman terendah $(8,23 \mathrm{~cm})$. Pertambahan tinggi tanaman diakibatkan terbentuknya sel-sel yang terbentuk di daerah meristem apikal dan berarti aktifitas pembelahan dan pemanjangan sel di pucuk merupakan inti dari pertumbuhan tinggi tanaman, kelancaran aktifitas pertumbuhan dipucuk yang tergantung pada suplai factor tumbuh terutama karbohidrat dari daun sebagai pusat fotosintesis [7]. Sintesis karbohidrat terjadi pada bagian-bagian hijau tanaman, terutama bagian daun tanaman yang mendapat sinar matahari langsung, dengan menggunakan unsur hara yang diserap tanaman sebagai bahan baku [8].

Pola tanam secara polikultur belum memberikan pertumbuhan yang signifikan pada tinggi tanaman sawi, namun tetap terjadi pertambahan tinggi tanaman setiap minggunya dikarenakan pupuk kompos 
kulit bawang merah yang yang dicampur dengan tanah mampu memperbaiki kesuburan media tumbuh. Tanah yang subur akan mampu menyediakan berbagai faktor tumbuh, seperti unsur hara dan air. Sebagaian besar unsur hara diambil tanaman dari tanaman lain (media) melalui perakaran. Unsur hara ini akan dimanfaatkan tanaman dalam aktifitas pertumbuhan (pembelahan dan pembesaran sel), sehingga tanaman semakin tinggi [9].

\subsection{Pengaruh Kompos Kulit Bawang \\ Merah Terhadap Jumlah Daun \\ Tanaman Sawi \\ Pengamatan daun tanaman} dilakukan 4 kali yaitu pada 7 HST, 14 HST, 21 HST, 28 HST. Data hasil pengamatan kemudian dianalisis menggunakan uji $\mathrm{F}$ dan untuk mengetahui perbedaan antar perlakuan dilakukan Uji Nyata Terkecil (BNT). Berdasarkan hasil penelitian, rataan respon polikultur sawi terhadap waktu pengomposan dan dosis kompos kulit bawang merah serta interaksinya terhadap tinggi tanaman dapat dilihat pada Tabel 6 .

Data pengamatan dan daftar sidik ragam jumlah daun tanaman sawi pada umur 7, 14, 21, dan 28 HST disajikan pada lampiran. Dari daftar sidik ragam menunjukkan bahwa respon polikultur cabai rawit terhadap waktu pengomposan dan dosis kompos kulit bawang merah serta interaksinya berpengaruh tidak nyata terhadap jumlah daun pada umur 7, 21, dan 28 HST tetapi berpengaruh nyata pada umur 14 HST. Dari Tabel 6 dapat dilihat bahwa pada semua perlakuan memperlihatkan perbedaan yang tidak nyata pada umur 7 HST, 21 HST, dan 28 HST serta menunjukkan perbedaan yang nyata pada umur 14 HST, dimana perlakuan P3W2 memperlihatkan jumlah daun yang paling banyak (6,75 helai) (dosis limbah kulit bawang merah 150 (gr) /polibag dan waktu pengomposan 36 jam).

Tabel 6. Rataan Hasil Uji BNT Pengaruh Perlakuan Terhadap Jumlah Daun Sawi

\begin{tabular}{llcll}
\hline \multirow{2}{*}{ Perlakuan } & \multicolumn{4}{l}{ Rata-rata Jumlah Daun (helai) } \\
\cline { 2 - 5 } & $7 \mathrm{HST}$ & $14 \mathrm{HST}$ & $21 \mathrm{HST}$ & $28 \mathrm{HST}$ \\
\hline P0W0 & $5,25 \mathrm{ab}$ & $5,75 \mathrm{a}$ & 5,50 & 8,25 \\
P1W1 & $5,00 \mathrm{ab}$ & $5,75 \mathrm{ab}$ & 6,50 & 9,50 \\
P1W2 & $5,75 \mathrm{ab}$ & $6,00 \mathrm{ab}$ & 6,25 & 8,50 \\
P2W1 & $5,75 \mathrm{ab}$ & $6,25 \mathrm{ab}$ & 6,25 & 9,25 \\
P2W2 & $5,00 \mathrm{ab}$ & $6,00 \mathrm{ab}$ & 6,25 & 9,50 \\
P3W1 & $5,5 \mathrm{~b}$ & $6,00 \mathrm{~b}$ & 6,25 & 8,75 \\
P3W2 & $5,75 \mathrm{~b}$ & $6,75 \mathrm{c}$ & 6,50 & 9,75 \\
\hline
\end{tabular}


Keterangan: angka dalam satu kolom yang diikuti huruf yang sama menunjukkan tidak berbeda nyata pada Uji BNT 5\%. (P0=tanpa kompos kulit bawang merah, P1=50 gr kompos/polibag, P2=100 gr/Polibag, P3 =150 gr/polibag, W1 umur kompos 24 jam, W2= umur kompos 36 jam)

Perlakuan POWO dan P3W2 pada umur 14 HST menunjukkan perbedaan yang signifikan. Hal ini di duga pemberian pupuk dengan kompos kulit bawang merah 150 (gr) /polibag dan waktu pengomposan 36 jam memberikan respon yang optimal terhadap jumlah daun tanaman sawi. Perlakuan P3W2, jika dibandingkan dengan perlakuan yang lain pun memberikan pengaruh yang signifikan (P1W1, P1W2, P2W2, P3W1) sedangkan dengan P2W1 memberikan respon yang sama. Campuran pupuk organik limbah kulit telur dan vetsin dengan penambahan rendaman kulit bawang merah memberikan pengaruh yang berbeda nyata terhadap tinggi tanaman, jumlah daun, dan biomassa tanaman [4]. Jumlah daun dengan pemberian perlakuan belum memberikan respon terhadap semua umur, diduga pengaruh jumlah daun lebih dominan dipengaruhi oleh faktor genetik dan faktor lingkungan [10]. Kecukupan dan ketersedian hara bagi tanaman tergantung pada macam macam dan jumlah hara tersebut pada tanah yang berada pada perimbangan sesuai dengan pertumbuhan tanaman. Tanaman dapat memenuhi siklus hidupnya dengan menggunakan hara.
Fungsi hara tanaman tidak dapat digantikan oleh unsur lain dan apabila tidak terdapat suatu hara tanaman, maka kegiatan metabolisme akan terganggu atau berhenti sama sekali. Jadi pada perlakuan yang memiliki pengaruh terbaik dapat dikatakan unsur hara yang tersedia cukup, sehingga proses metabolisme tanaman tidak terganggu [11].

\subsection{Pengaruh Kompos Kulit Bawang Merah Terhadap Panjang Daun Tanaman Sawi \\ Pengamatan panjang daun} tanaman dilakukan 4 kali yaitu pada 7 HST, 14 HST, 21 HST, 28 HST. Data hasil pengamatan kemudian dianalisis menggunakan uji $\mathrm{F}$ dan untuk mengetahui perbedaan antar perlakuan dilakukan Uji Nyata Terkecil (BNT). Berdasarkan hasil penelitian, pengaruh pemberian pupuk kompos terhadap panjang daun tanaman dapat dilihat pada Tabel 7.

Perlakuan P2W1 memperlihatkan rataan panjang daun tertinggi sebesar $12,85 \mathrm{~cm} \quad(28$ HST $)$ sedangkan P3W1 memperlihatkan rataan panjang daun terendah sebesar $(10,95 \mathrm{~cm})$. Hasil analisis sidik ragam pada lampiran dapat diketahui bahwa tidak adanya pengaruh yang 


\section{Jurnal IImiah Respati}

signifikan $(p>0,05)$ pada jumlah daun tanaman sawi hijau baik pada 7 HST, 14 HST, 21 HST, dan 28 HST. Artinya pemberian pupuk kompos kulit bawang dan waktu pengomposan sampai tingkat 150 gram/polibag (P3) terhadap jumlah daun tanaman sawi hijau memberikan pengaruh yang sama dengan kontrol (PO).

Pengaruh pemupukan kompos kulit bawang merah belum memberikan efek yang nyata terhadap panjang daun tanaman sawi hijau. Meskipun pemberian kompos kulit bawang tidak berpengaruh nyata terhadap pertumbuhan daun tanaman sawi hijau, diduga karena penyerapan unsur hara yang terkandung dalam pupuk kompos kulit bawang lambat.
Namun pertumbuhan dari 7 HST, 14 HST, 21 HST, 28 HST sampai 35 HST cenderung bertingkat sehingga dapat dikatakan baik. Selain itu, karena diduga pada tanah yang digunakan sudah terdapat unsur hara yang cukup untuk diserap tanaman, sehingga dengan perlakuan $0 \%$ pun telah mampu memberikan pengaruh yang tinggi. Pengaruh yang tidak berbeda nyata dipengaruhi oleh cuaca yang tidak stabil kadang cahaya matahari panas kadang mendung sehingga proses fotosintesis dan pertumbuhan tanaman terganggu yang mengakibatkan tidak menimbulkan pengaruh yang berbeda nyata terhadap panjang daun sawi [12].

Tabel 7. Rataan Hasil Uji BNT Pengaruh Perlakuan Terhadap Panjang Daun

\begin{tabular}{cllll}
\hline \multirow{2}{*}{ Perlakuan } & \multicolumn{4}{c}{ Rata-rata Panjang Daun (cm) } \\
\cline { 2 - 5 } & 7 HST & 14 HST & 21 HST & 28 HST \\
\hline P0W0 & 3,60 & 4,40 & 8,53 & 11,70 \\
P1W1 & 4,40 & 4,50 & 9,15 & 11,85 \\
P1W2 & 4,40 & 4,30 & 7,33 & 11,25 \\
P2W1 & 4,80 & 5,50 & 10,90 & 12,85 \\
P2W2 & 4,70 & 5,20 & 8,85 & 12,58 \\
P3W1 & 4,80 & 5,90 & 9,00 & 10,95 \\
P3W2 & 4,10 & 4,80 & 9,60 & 11,30
\end{tabular}

Keterangan : angka dalam satu kolom yang diikuti huruf yang sama menunjukkan tidak berbeda nyata pada Uji BNT 5\%. (P0=tanpa kompos kulit bawang merah, $\mathrm{P} 1=50 \mathrm{gr}$ kompos/polibag, P2=100 gr/Polibag, P3 =150 gr/polibag, W1 umur kompos 24 jam, W2= umur kompos 36 jam) 


\subsection{Pengaruh Kompos Kulit Bawang Merah Terhadap Bobot Basah Tanaman Sawi}

Pengamatan bobot basah tanaman dilakukan 4 kali yaitu pada 7 HST, 14 HST, 21 HST, 28 HST. Data hasil pengamatan kemudian dianalisis menggunakan uji $\mathrm{F}$ dan untuk mengetahui perbedaan antar perlakuan dilakukan Uji Nyata Terkecil (BNT). Berdasarkan hasil penelitian, pengaruh pemberian pupuk kompos terhadap bobot basah tanaman dapat dilihat pada Tabel 8. Berdasarkan Tabel 8, nilai rataan bobot basah tanaman sawi hijau secara berurutan (P2W1) 180,50 gram, (POW0) 142,50 gram, (P3W2) 128,25 gram, (P2W2) 126,25 gram (P1W1) 124,50 gram, (P1W2) 115,75 gram dan (P3W1) 114,50 gram. Guna mengetahui pengaruh perlakuan terhadap bobot basah maka dilakukan analisis sidik ragam.

Tabel 8. Rataan Hasil Uji BNT Pengaruh Perlakuan Terhadap Bobot Basah.

\begin{tabular}{cc}
\hline Perlakuan & Rata-rata Bobot Basah (gram) \\
\hline P0W0 & 142,50 \\
P1W1 & 124,50 \\
P1W2 & 115,75 \\
P2W1 & 180,50 \\
P2W2 & 126,25 \\
P3W1 & 114,50 \\
P3W2 & 128,25
\end{tabular}

Keterangan: angka dalam satu kolom yang diikuti huruf yang sama menunjukkan tidak berbeda nyata pada Uji BNT 5\%. (P0=tanpa kompos kulit bawang merah, $\mathrm{P} 1=50$ gr kompos/polibag, P2=100 gr/Polibag, P3 =150 gr/polibag, W1 umur kompos 24 jam, W2= umur kompos 36 jam).

Hasil analisis sidik ragam dapat dilihat bahwa tidak adanya pengaruh yang signifikan $(p>0,05)$ pada bobot basah tanaman sawi hijau. Perlakuan P3W1 menghasilkan bobot basah tanaman sawi hijau terkecil (114,50 gram) dan perlakuan (P2W1) terbesar (180,50 gram). Dari data tersebut dapat diketahui bahwa pemberian dosis kompos limbah kulit bawang merah dan waktu pengomposan memberikan pengaruh yang tidak nyata terhadap tanaman sawi. Salah satu faktor lingkungan yang sangat menentukan laju pertumbuhan pada tanaman adalah ketersedian unsur hara, sebagian besar 
bobot basah tanaman disebabkan kandungan air.

$$
\text { Hasil analisis sidik ragam }
$$

menunjukkan tidak terdapat interaksi antara perlakuan kompos kulit bawang dengan waktu pengomposan. Hal ini diduga tanaman sawi dengan dua perlakuan tersebut memiliki jumlah daun dan panjang daun yang lebih rendah dari kontrol, sehingga menyebabkan bobot basah juga lebih rendah daripada kontrol. Bobot basah tanaman umumnya sangat berfluktuasi, tergantung pada keadaan kelembaban tanaman. Peningkatan hasil bobot basah tanaman dapat mencapai hasil yang optimal, karena tanaman memperoleh hara yang dibutuhkan sehingga peningkatan jumlah maupun ukuran sel dapat mencapai optimal serta dapat meningkatan kandungan air tanaman yang optimal pula. Air pun akan membantu meningkatkan pertumbuhan tanaman melalui fungsi penting tersebut. Inilah yang menyebabkan berat basah pada tanaman sawi hijau yang diberi perlakuan dan tidak diberikan perlakuan memiliki bobot basah yang sama [13].

\section{SIMPULAN}

Interaksi kompos kulit bawang merah dan waktu pengomposan berpengaruh terhadap bobot basah dan bobot buah cabai rawit merah yang dibudidayakan secara polikultur.
Pemberian 100 gram/polibag kompos kulit bawang merah umur 36 jam (P2W2) menghasilkan bobot tanaman dan bobot buah cabai rawit tertinggi yaitu masing 211,25 gram dan 73,25 gram.

\section{DAFTAR PUSTAKA}

[1] Anonim, 2017. Teknologi Penggunaan Kompos Bawang Merah Sebagai Campuran Media Tanam dan Media Semai Tanaman Hortikultura di DKI Jakarta. Balai Pengkajian dan Penerapan Teknologi Pertanian. Jakarta

[2] Haryanto, Eko. 2007. Sawi dan Selada. Jakarta :Penebar Swadaya. 112 hal

[3] Muswita. 2011. Pengaruh Konsentrasi Bawang Merah (Alium cepa L.) terhadap Pertumbuhan setek Gaharu. Jurnal Penelitian Universitas Jambi Seri Sains

[4] Noviansah, B. 2014. Aplikasi pupuk organik campuran limbah kulit telur dan vetsin dengan penambahan rendaman kulit bawang merah terhadap pertumbuhan tanaman cabai keriting (Capsicum annum L.) var Longum. Skripsi Fakultas Keguruan.

[5] Campbell, N. A. 2005. Biologi Edisi Kelima Jilid II . Jakarta: Erlangga.

[6] Vintina, I.V. 2014. Respon Varietas Tanaman Jagung (Zea mays) terhadap Cekaman Kekeringan pada Fase Pertumbuhan Vegetatif. Skripsi. 
Universitas Pembangunan Nasional Veteran Jawa Timur

[7] Allard. (2001). Pemuliaan Tanaman. Bina Aksara. Jakarta.

[8] Sutanto, R., 2002. Penerapan Pertanian Organik: Pemasyarakatan dan Pengembangannya. Yogyakarta.

[9] Indriani. (2007). Membuat Kompos Secara Kilat. Jakarta: Penebar Swadaya.

[10] Hutagalung, O.E.H. (2006). Pengantar Genetika. Universitas Katolik St. Thomas Sumatera Utara. Medan.

[11] Baning, C. Rahmatan, H. dan Suprianto. 2016. Pengaruh pemberian air cucian beras merah terhadap pertumbuhan vegetatif tanaman lada (Piper nigrum L.). Jurnal IImiah Mahasiswa Pendidikan Biologi, Vol 1. Issue 1.

[12] Bahuwa, S., Musa, N., dan Zakaria, F. 2014. Pertumbuhan dan hasil tanaman sawi (Brassica juncea L.) menggunakan air cucian beras dan jarak tanam. Jurusaan Agroteknologi, Fakultas Pertanian, Universitas Negeri Gorontalo.

[13] Rahman, A., C. D Lasiwua. 2011. Aplikasi Pupuk Organik Cair Terhadap Pertumbuhan dan Produksi Tanaman Sawi. [Skripsi]. STPP Gowa. Pertanian Bogor. 